EPiC Series in Engineering
Volume 3, 2018, Pages 1935-1944
HIC 2018. 13th International
Conference on Hydroinformatics

\title{
Rainfall Trends over the Past Century for Tropical Climatic Region in Western India
}

\author{
Priyank J. Sharma ${ }^{1}$ and P. L. Pate ${ }^{2 *}$ \\ ${ }^{1}$ DST INSPIRE Fellow, Department of Civil Engineering, Sardar Vallabhbhai National Institute \\ of Technology, Surat - 395007, India. \\ ${ }^{2}$ Professor, Department of Civil Engineering, Sardar Vallabhbhai National Institute of \\ Technology, Surat - 395007, India. \\ pjs230688@gmail.com, premlalpatel1966@gmail.com
}

\begin{abstract}
Present study examines the applications of different trend detection methodologies for investigation of trend in long-term rainfall over Lower Tapi basin, India using daily gridded rainfall data for the period $1901-2013$ at $0.25^{\circ} \times 0.25^{\circ}$ resolution. The trends in rainfall indices, viz. total annual rainfall (TAR), annual maximum rainfall (AMR) and average annual rainfall intensity (AAI) have been detected using non-parametric and graphical methods. The results show increasing trends in TAR across all the 9 grids in the study region, with significant increasing trend over Grids-8 and 9. Further, AMR exhibited increasing trend over 7 out of 9 grids, with significant increasing trend over Grid-8 $\left(Z_{M M K}=2.478 ; \beta=0.356 \mathrm{~mm} /\right.$ year $)$ and Grid-9 $\left(Z_{M M K}=2.278 ; \beta=0.257\right.$ $\mathrm{mm} / \mathrm{year}$ ). The Innovative Trend Analysis plots reveal overall increasing trend in AMR across all the grids. The AAI exhibited significant increasing trend over 5 grids including Grids- 8 and 9. The Grids 8 and 9 encompass the urban areas of the Surat city, located in the Lower Tapi basin. The urbanization in the Surat city and proximity to the Arabian Sea areas may be the possible reasons for significant increase in the extreme rainfall and rainfall intensity over Grids-8 and 9.
\end{abstract}

\section{Introduction}

The changes in rainfall pattern due to global warming, and its influence on hydrological cycle and stream flows at basin scale, require a review of existing hydrologic design and water management practices. The changes in runoff pattern and its distribution at basin scale, depend on possible trends in climatic parameters across the basin. The decreasing trends of total rainfall and increasing trends of maximum rainfall intensity were reported in previous investigations across the globe (Martinez et al.,

\footnotetext{
${ }^{*}$ Corresponding author
} 
2012; Soro et al., 2016; He et al., 2017). Previous studies (Goswami et al., 2006; Guhathakurta and Rajeevan, 2008; Dash et al., 2009; Ghosh et al., 2009) demonstrated increase in extreme rainfall events across India. Prakash et al. (2013) found decrease in long-term monsoon rainfall across the west coast of India, however, increasing trend has been observed in the recent years from 2002 onwards. Pai et al. (2014) analyzed high-resolution $\left(0.25^{\circ} \times 0.25^{\circ}\right)$ gridded rainfall data, and found an increasing trend in very heavy rainfall events over central India. Sharma et al. (2015) reported a rising trend in annual rainfall across Surat district over a period of 110 years (1901-2010), with significant increase during the decade 2001-2010. Ghosh et al. (2016) reported contrasting spatial variabilities of mean and extreme Indian Summer Monsoon Rainfall (ISMR), wherein the mean monsoon rainfall was found to decrease over India. Dave and James (2017) reported significant increasing trend in average monsoon rainfall in Gujarat state (India) during the period 1970-2014, with an increase of $48 \mathrm{~mm} /$ decade. Sharma et al. (2017) analyzed the trends in extreme climatic indices at finer spatial scales, and found decreasing trend in annual rainfall, rainy days, consecutive wet days while increasing trend in rainfall intensity and consecutive dry days across Upper Tapi basin, India. Further, the increase in frequency and magnitude of extreme rainfall were attributed to the increase in temperature and anthropogenic forcing. A threefold increase in extreme rain events over central India was found during the past 65 years (1950-2015) (Roxy et al., 2017). The rise in such events were attributed to the increasing variability of the low-level monsoon westerlies over the Arabian Sea, driving surges of moisture supply, leading to extreme rainfall occurrences across the entire central India. Present study aims to examine the variability and trends in rainfall indices over the past century across Lower Tapi basin in India, using existing statistical nonparametric and graphical trend detection techniques.

\section{Materials and Methods}

\subsection{Study Area and Data Used}

The Tapi basin is the second largest basin in western India spread across a geographical area of $65,145 \mathrm{~km}^{2}$. The Tapi River, having a length of $724 \mathrm{~km}$, drains into the Arabian Sea. The Lower Tapi basin $\left(\right.$ area $\approx 2790 \mathrm{~km}^{2}$ ) is marked from Ukai dam to the Arabian Sea. The Surat city is located on the coastal urban flood plain of lower Tapi River and situated at $95 \mathrm{~km}$ downstream of Ukai dam. The Tapi River historically brought intense floods in the Surat city during the years 1727, 1776, 1782, 1829, 1837, 1872, 1944, 1959, 1968, 1970, 1994, 1998, 2006 and 2013 (Kale and Hire, 2004; Timbadiya et al., 2014). Further, the riverine floods become more severe as and when heavy rainfalls in the region accompany the same. The 2006 flood in Surat city was a combination of riverine, tidal and urban floods, wherein economic losses up to $\$ 4.2$ billion were estimated and many other casualties were reported (Timbadiya et al., 2014). The inland peninsular India, except for a semi-arid rain shadow east of the Western Ghats, experiences a tropical wet and dry climate. The climate of Lower Tapi basin is categorized as Tropical Savanna Climate $(A w)$ as per Köppen-Geiger climate classification (Peel et al., 2007). The average annual rainfall in the basin varies from $900-1500 \mathrm{~mm}$, while average annual temperature is around $27.8^{\circ} \mathrm{C}(\mathrm{CGWB}, 2013)$. The $0.25^{\circ} \times 0.25^{\circ}$ daily gridded rainfall data prepared by the India Meteorological Department (IMD) for the India have been used for analyses in the present study. The Lower Tapi basin encompasses nine grids. The daily rainfall data of previously mentioned grids have been extracted and analyzed further. The index map of the study area with grid labels is shown in Figure 1. The Tapi basin receives intense rainfall during the southwest monsoon, due to lowpressure systems generated from the Bay of Bengal as well as due to striking of monsoonal winds from the Arabian Sea with Western Ghats, which is primarily responsible for high-magnitude floods in Tapi River (Kale et al., 1994). The Lower Tapi basin, bearing its geographical proximity to the Arabian Sea, receives higher rainfall compared to Middle and Upper Tapi basins due to loss of moisture as the clouds 
move landwards. The extent of urbanization in Surat city can be gauged from the fact that the city limits extended from $8.18 \mathrm{~km}^{2}$ in year 1961 to $362.515 \mathrm{~km}^{2}$ in year 2006. The population of Surat city reported an increase of $65.52 \%$ during the decade 2001-2011 (www.censusindia.gov.in).

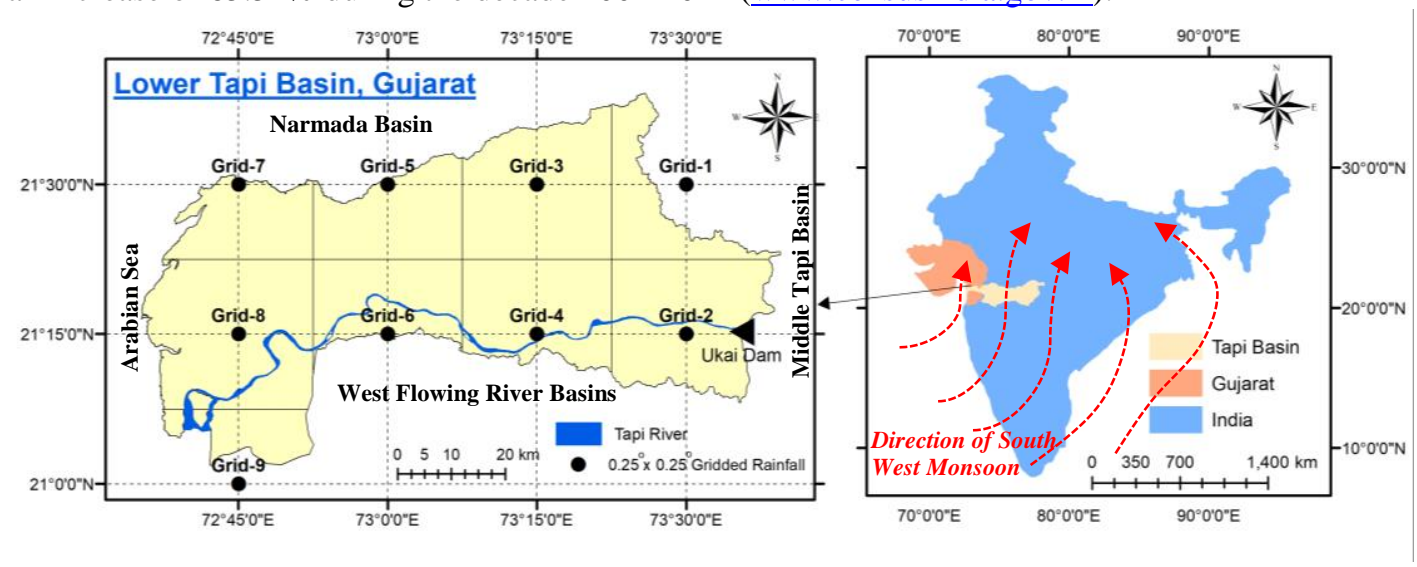

Figure 1: Index map of Lower Tapi basin

\subsection{Methodology}

The methodology adopted in the present study is as under:

i. The time series of daily rainfall data $\left(0.25^{\circ} \times 0.25^{\circ}\right.$ resolution) for the grids shown in Figure 1 were extracted from the IMD data set of entire India (Pai et al., 2014).

ii. The time series of total annual rainfall (TAR), annual maximum rainfall (AMR) and average annual rainfall intensity (AAI) were derived for each grid point for period of 113 years (1901-2013).

iii. The time series were checked for the presence of serial correlation (Yue and Hashino, 2003), if any. The serially correlated data were pre-whitened before application of non-parametric tests (Burn and Elnur, 2002), i.e., Mann-Kendall (MK) and Spearman's Rho (SR) tests (Mann, 1945; Kendall, 1975; Lehmann, 1975).

iv. The Modified Mann-Kendall (MMK) test (Hamed and Rao, 1998) was applied for serially correlated data to examine the significance of the trends.

v. The Sen's slope estimator test (Hirsch et al., 1982) was applied to detect the changes in magnitude of trend.

vi. The Innovative Trend Analysis (ITA) methodology developed by Şen (Sen, 2011) is also applied to detect the trends in the regimes of climatic variables, viz., low, moderate and high.

vii. The short-term and long-term fluctuations in rainfall indices during the study period have been studied by applying the Cramer's $t$ test (WMO, 1966) on 11- and 31-year moving means.

\section{Results and Discussion}

\subsection{Rainfall Distribution across Lower Tapi Basin}

The total annual rainfall (TAR) was computed for each grid from the daily rainfall for the period of 113 years. The histogram in Figure 2 shows the frequency distribution of TAR at each grid. Here, the ordinate represents the frequency of occurrence of annual rainfall in a particular class interval marked in abscissa. Based upon the criteria suggested by Yoo (2006), the meteorological conditions in the basin were classified as dry, normal and wet years. For instance, if TAR for a given grid in a particular year is greater than $\left(\mathrm{P}_{\text {mean }}+0.75 \mathrm{SD}\right)$, it is classified as wet year; if TAR is less than $\left(\mathrm{P}_{\text {mean }}-0.75 \mathrm{SD}\right)$, it is 
dry year; otherwise normal year. Here, $\mathrm{P}_{\text {mean }}$ and $\mathrm{SD}$ refers to the mean and standard deviation of TAR of entire Lower Tapi basin observed during the period 1901-2013. The Grids-2, 4, 6 and 9 were found to exhibit wet regimes for more than $23 \%$ of time, with the maximum of $30.1 \%$ at Grid-4. On the other hand, Grids-5, 7 and 8 reported dry regimes more than $25 \%$ of time, wherein Grid- 7 experienced dry years for around $54.9 \%$ of time during the total study period. This indicates a very high variability in the rainfall distribution within the basin. The grids adjacent to the southern boundary of the basin experience larger wet regimes compared to the grids adjacent to the northern boundary.
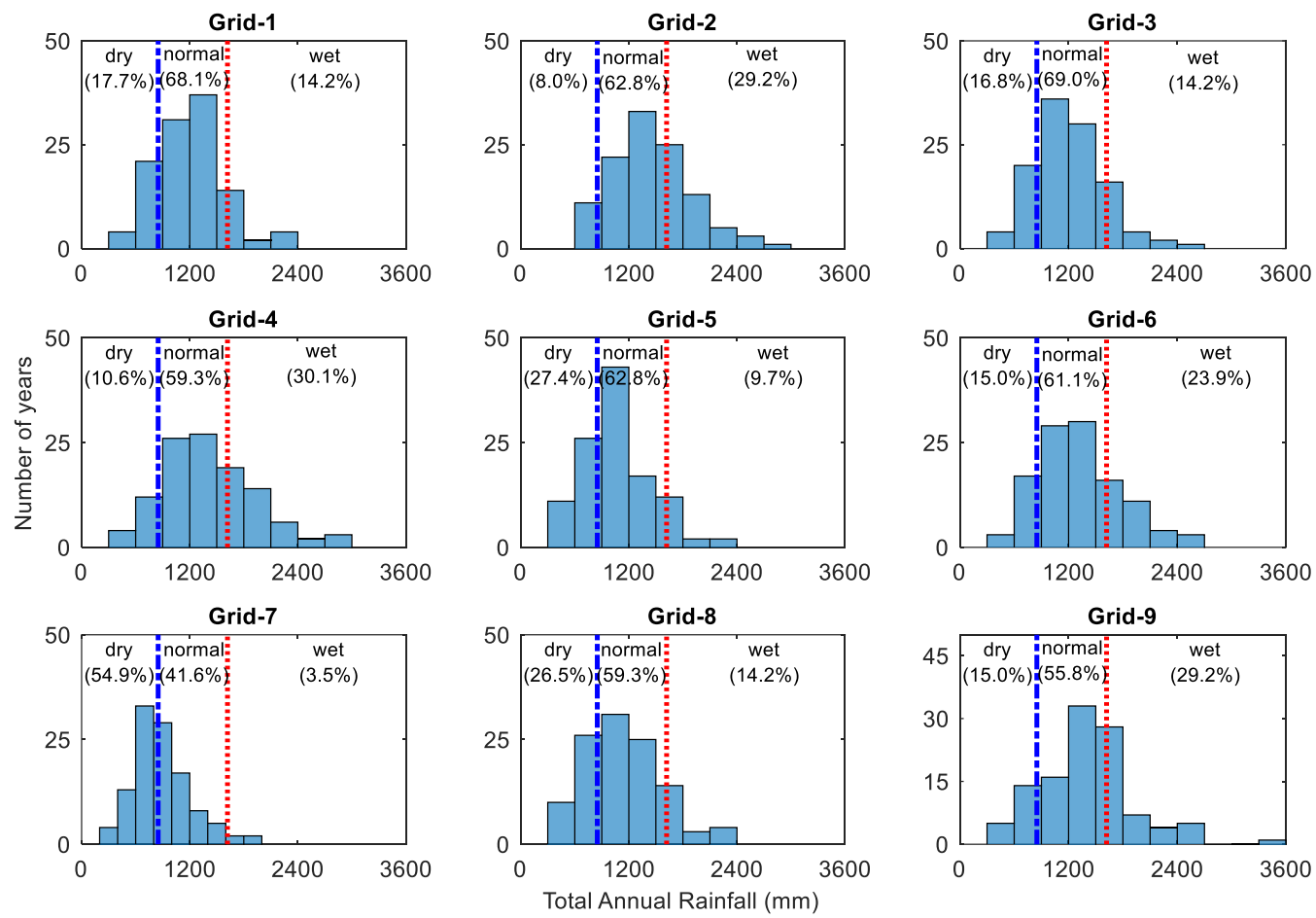

Figure 2: Histogram of total annual rainfall and distribution of different meteorological conditions. The dashed dotted line (-.-.-) represents the lower threshold ( $\left.\mathrm{P}_{\text {mean }}-0.75 \mathrm{SD}\right)$, while the dotted line (.....) represents the upper threshold $\left(\mathrm{P}_{\text {mean }}+0.75 \mathrm{SD}\right)$.

\subsection{Trends in Rainfall Magnitude}

The average TAR across the basin was found to vary from $884.8 \mathrm{~mm}$ (Grid-7) to $1441.3 \mathrm{~mm}$ (Grid2). It is found that Grids-2, 4 and 9 receive average annual rainfall greater than $1400 \mathrm{~mm}$, thereby, indicating that southern part of the basin receives heavy rainfall. The Grids- 8 and 9 encompass the urban areas of Surat city, while the remaining grids cover rural and agricultural areas. The trend analyses of TAR exhibit increasing trends over all the 9 grids in the basin (see Table 1). Further, significant increasing trends are observed at Grids-8 and 9 having MMK Z-statistics of 2.150 and 2.407 respectively. The ITA plots (not included due to paucity of space) also clearly reflect increasing trend in TAR across all the grids for all hydrologic regimes, viz., low, medium and high magnitudes. The increasing trend in annual rainfall would imply increase in water availability for agricultural, municipal and industrial needs of the basin. The increased water availability would result in increased yields for the major crops such as are paddy, jowar, bajra, vegetables, wheat, sugarcane, groundnut, cotton, banana, fodder, and other cash crops, cultivated in Ukai-Kakrapar command area (Sharma et al., 2016). 
Rainfall Trends over the Past Century for Tropical Climatic Region in ...P. J. Sharma and P. L. Patel

Table 1: Results of statistical trend detection tests for total annual rainfall in Lower Tapi basin

\begin{tabular}{ccccccccc}
\hline \multirow{2}{*}{ Grid } & \multicolumn{2}{c}{ MK test } & \multicolumn{2}{c}{ SR test } & Sen's slope test & \multicolumn{2}{c}{ MMK test } & \multirow{2}{*}{$\begin{array}{c}\text { Nature } \\
\text { of trend }\end{array}$} \\
\cline { 2 - 7 } & $Z$ & $p$-value & $t_{s}^{*}$ & $p$-value & $\beta$ (mm/year) & $Z$ & $p$-value & o \\
\hline Grid-1 & 0.221 & 0.825 & 0.191 & 0.849 & 0.263 & 0.291 & 0.771 & $\uparrow$ \\
Grid-2 & 0.285 & 0.775 & 0.239 & 0.812 & 0.353 & 0.289 & 0.773 & $\uparrow$ \\
Grid-3 & 0.027 & 0.978 & 0.075 & 0.940 & 0.040 & 0.033 & 0.974 & $\uparrow$ \\
Grid-4 & 1.551 & 0.121 & 1.563 & 0.121 & 2.220 & 1.551 & 0.121 & $\uparrow$ \\
Grid-5 & 1.665 & 0.096 & 1.658 & 0.100 & 1.825 & 1.497 & 0.134 & $\uparrow$ \\
Grid-6 & 0.732 & 0.464 & 0.821 & 0.413 & 1.026 & 0.732 & 0.464 & $\uparrow$ \\
Grid-7 & 1.603 & 0.109 & 1.671 & 0.098 & 1.379 & 1.603 & 0.109 & $\uparrow$ \\
Grid-8 & $\mathbf{2 . 2 6 5}$ & $\mathbf{0 . 0 2 3}$ & $\mathbf{2 . 2 8 0}$ & $\mathbf{0 . 0 2 4}$ & 2.819 & $\mathbf{2 . 1 5 0}$ & $\mathbf{0 . 0 3 2}$ & $\Uparrow$ \\
Grid-9 & $\mathbf{2 . 7 6 2}$ & $\mathbf{0 . 0 0 6}$ & $\mathbf{2 . 8 0 5}$ & $\mathbf{0 . 0 0 6}$ & 3.991 & $\mathbf{2 . 4 0 7}$ & $\mathbf{0 . 0 1 6}$ & $\Uparrow$ \\
\hline
\end{tabular}

* Critical value of test statistic at 5\% significance level and $n-2$ degrees of freedom was 1.982 .

Bold values indicate that trends were statistically significant at $5 \%$ significance level.

$\uparrow$ denotes increasing trend and $\Uparrow$ denotes significant increasing trend.

\subsection{Trends in Extreme Rainfall and Rainfall Intensity}

The daily annual maximum rainfall calculated for all the grids reveal that AMR varies from 110.4 $\mathrm{mm}$ at Grid-7 to $156.9 \mathrm{~mm}$ at Grid-4 in the basin. Further, the historical data reveals that maximum daily rainfall of $532.7 \mathrm{~mm}$ was recorded at Grid-9 in the year 1941, whereas, in the same year, the adjoining Grid-8 recorded $400.4 \mathrm{~mm}$ daily rainfall. The proximity of Lower Tapi basin to large water mass (i.e. The Arabian Sea) is responsible for efficient transport of moisture and, thereby, results in heavy convective and cyclonic precipitation in the region. The trend analysis of AMR showed increasing trends over 7 grids, while decreasing trends are observed at 2 grids (Grids-1 and 3), see Table 2. Further, the ITA plots reveal overall increasing trend in AMR; however, decreasing trends are observed in rainfall of higher magnitudes across most of the grids. The AAI has been found to be increasing over 8 out of 9 grids in the basin, whereas decreasing trend is reported only for Grid-1 (see Table 3). Overall, 5 grids reported significant increasing trends in AAI including Grids-8 and 9. The increase in rainfall intensity coupled with rapidly transforming natural landscapes in the form of paved surfaces would make the Surat city more vulnerable to urban flood hazards in near future. This clearly indicates the requirement of upgrading existing storm water network (SWN), proper operational maintenance of SWN, and creation of detention ponds to avert urban flood hazards in the Surat city due to changes in climatic variables. The vulnerability of Surat city to flooding would increase manifolds in near future due to increasing trend of AMR and AAI, and exposure of city to severe riverine floods in recent past (Timbadiya et al., 2014).

\subsection{Short-term and Long-term Rainfall Fluctuations}

The Cramer's $t$-test has been applied to 11- and 31-year moving average (MA) series to detect the fluctuations in rainfall across the basin, see Figure 3. It is seen that 11-year MA for TAR showed rising trends upto $1942\left(t_{k}=3.45\right.$, significant at $1 \%$ level $)$ for Grid-2, and thereafter decreasing trends; whereas, for Grid-7 the highest value was found in $2008\left(t_{k}=3.79\right.$, significant at $1 \%$ level $)$. Further, the 31-year MA also displayed similar pattern of rainfall fluctuations as displayed by 11-year MA. Moreover, the lowest values for Grids-2, 4, 7 and 9 for both 11- and 31-year MA were found to be consistent around 1906 and 1916 respectively. The Grids-8 and 9 exhibited highest value of $t_{k}$ for 11year MA in 2008, indicating a significant rise in the rainfall in recent past decades (i.e., 2003-2013). 
Rainfall Trends over the Past Century for Tropical Climatic Region in ...P. J. Sharma and P. L. Patel

The AMR, on the other hand, displayed larger fluctuations, wherein the lowest values for 11-year MA were found during the years 1952-1960 for all the grids, while the variability in highest values were quite distributed along the timeline. The 11-year MA of AMR (for all grids) were found to be more significant than 31-year MA, which reflect that the short-term climatic fluctuations are more prominent compared to the long-term fluctuations. The Grids-2, 4 and 7 had $t_{k}$-statistics of 3.90, 3.71 and 3.54 for 11-year MA, indicating significant deviation from the mean values at $1 \%$ significance level also. The AAI showed monotonic increasing trends in 31-year means for the Grids-2, 4, 8 and 9 up to the years 1991, 1955, 1994 and 1991 respectively. The lowest points for 31-year means for the Grids-2, 4, 8 and 9 were found to be 1916, 1921, 1921 and 1916 respectively.

Table 2: Results of statistical trend detection tests for annual maximum rainfall in Lower Tapi basin

\begin{tabular}{ccccccccc}
\hline \multirow{2}{*}{ Grid } & \multicolumn{2}{c}{ MK test } & \multicolumn{2}{c}{ SR test } & Sen's slope test & \multicolumn{2}{c}{ MMK test } & \multirow{2}{*}{$\begin{array}{c}\text { Nature } \\
\text { of trend }\end{array}$} \\
\cline { 2 - 8 } & $Z$ & $p$-value & $t_{s}^{*}$ & $p$-value & $\beta$ (mm/year) & $Z$ & $p$-value & (m) \\
\hline Grid-1 & -0.457 & 0.648 & -0.055 & -0.585 & -0.048 & -0.457 & 0.648 & $\downarrow$ \\
Grid-2 & 1.196 & 0.232 & 0.110 & 1.171 & 0.196 & 1.258 & 0.208 & $\uparrow$ \\
Grid-3 & -0.576 & 0.564 & -0.066 & -0.700 & -0.081 & -0.689 & 0.491 & $\downarrow$ \\
Grid-4 & 0.263 & 0.793 & 0.022 & 0.236 & 0.040 & 0.756 & 0.450 & $\uparrow$ \\
Grid-5 & 0.608 & 0.543 & 0.062 & 0.652 & 0.085 & 0.727 & 0.467 & $\uparrow$ \\
Grid-6 & 0.479 & 0.632 & 0.045 & 0.477 & 0.070 & 0.564 & 0.573 & $\uparrow$ \\
Grid-7 & 0.015 & 0.988 & 0.003 & 0.037 & 0.002 & 0.020 & 0.984 & $\uparrow$ \\
Grid-8 & $\mathbf{2 . 2 5 6}$ & $\mathbf{0 . 0 2 4}$ & 0.212 & $\mathbf{2 . 2 8 4}$ & 0.356 & $\mathbf{2 . 4 7 8}$ & $\mathbf{0 . 0 1 3}$ & $\Uparrow$ \\
Grid-9 & $\mathbf{1 . 6 5 3}$ & $\mathbf{0 . 0 9 8}$ & 0.162 & 1.728 & 0.257 & $\mathbf{2 . 2 7 8}$ & $\mathbf{0 . 0 2 3}$ & $\Uparrow$ \\
\hline
\end{tabular}

* Critical value of test statistic at 5\% significance level and $n-2$ degrees of freedom was 1.982.

Bold values indicate that trends were statistically significant at $5 \%$ significance level.

$\downarrow$ denotes decreasing trend, $\uparrow$ denotes increasing trend and $\Uparrow$ denotes significant increasing trend.

Table 3: Results of statistical trend detection tests for average annual rainfall intensity in Lower Tapi basin

\begin{tabular}{|c|c|c|c|c|c|c|c|c|}
\hline \multirow[b]{2}{*}{ Grid } & \multicolumn{2}{|c|}{ MK test } & \multicolumn{2}{|c|}{ SR test } & \multirow{2}{*}{$\begin{array}{c}\text { Sen's slope test } \\
\beta \text { (mm.day }^{-1} \\
\text { /year })\end{array}$} & \multicolumn{2}{|c|}{ MMK test } & \multirow{2}{*}{$\begin{array}{l}\text { Nature } \\
\text { of trend }\end{array}$} \\
\hline & $Z$ & $p$-value & $t_{s}^{*}$ & $p$-value & & $Z$ & $p$-value & \\
\hline Grid-1 & -0.136 & 0.892 & -0.232 & 0.817 & -0.002 & -0.157 & 0.876 & $\downarrow$ \\
\hline Grid-2 & 3.456 & 0.001 & 3.599 & 0.000 & 0.048 & 3.741 & 0.000 & $\Uparrow$ \\
\hline Grid-3 & 1.412 & 0.158 & 1.433 & 0.155 & 0.017 & 1.412 & 0.158 & $\uparrow$ \\
\hline Grid-4 & 1.819 & 0.068 & 1.967 & 0.052 & 0.032 & 1.544 & 0.122 & $\uparrow$ \\
\hline Grid-5 & 2.504 & 0.013 & 2.620 & 0.010 & 0.032 & 2.828 & 0.005 & $\Uparrow$ \\
\hline Grid-6 & 2.484 & 0.013 & 2.605 & 0.010 & 0.037 & 2.908 & 0.004 & $\Uparrow$ \\
\hline Grid-7 & 1.690 & 0.091 & 1.712 & 0.090 & 0.022 & 1.690 & 0.091 & $\uparrow$ \\
\hline Grid-8 & 3.759 & 0.000 & 4.029 & 0.000 & 0.065 & 3.684 & 0.000 & $\Uparrow$ \\
\hline Grid-9 & 2.603 & 0.010 & 2.675 & 0.009 & 0.046 & 2.593 & 0.010 & $\Uparrow$ \\
\hline
\end{tabular}

* Critical value of test statistic at 5\% significance level and $n-2$ degrees of freedom was 1.982.

Bold values indicate that trends were statistically significant at $5 \%$ significance level.

$\downarrow$ denotes decreasing trend, $\uparrow$ denotes increasing trend and $\Uparrow$ denotes significant increasing trend. 
Rainfall Trends over the Past Century for Tropical Climatic Region in ...P. J. Sharma and P. L. Patel

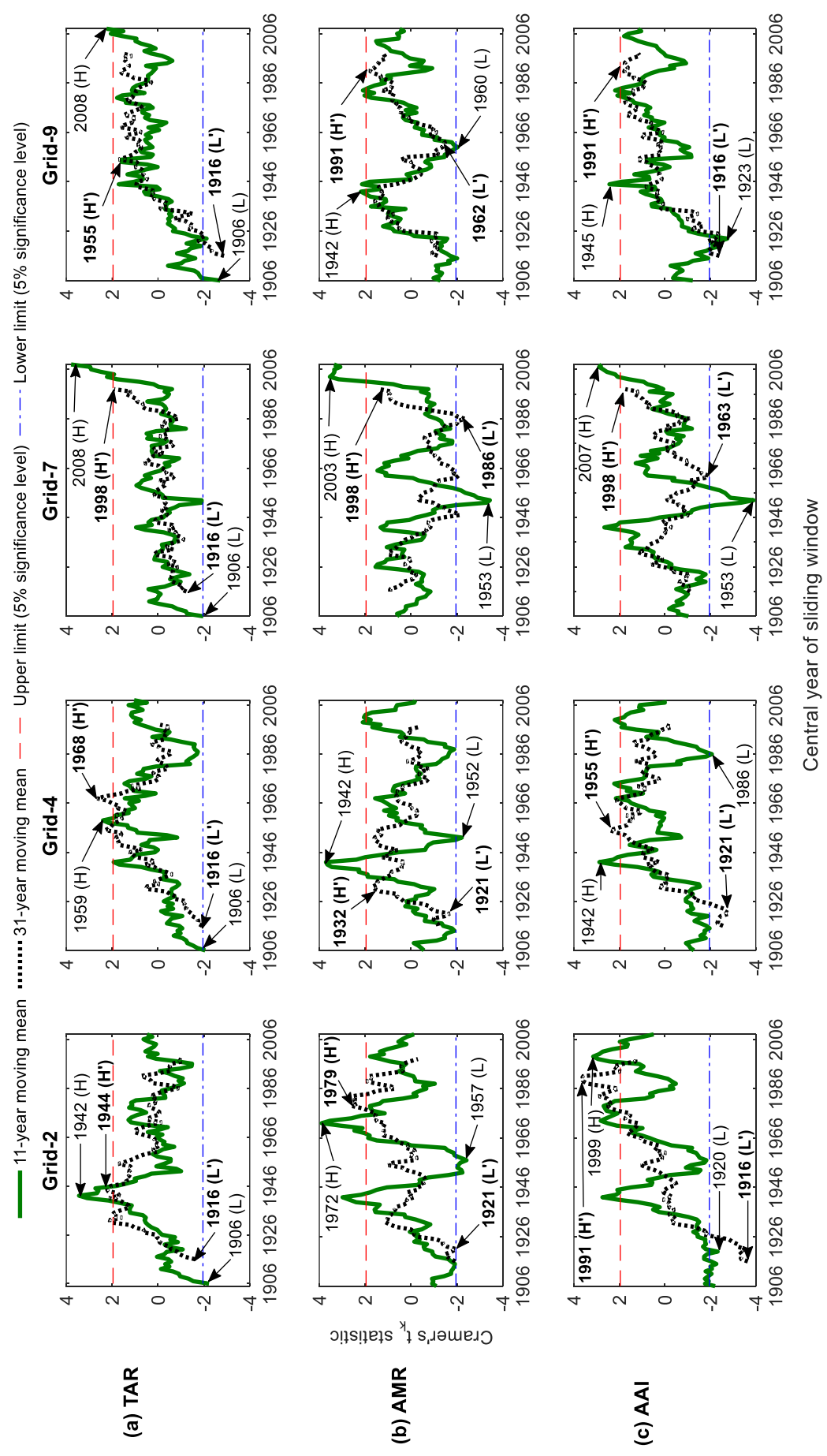

Figure 3: The Cramer's $t_{k}$-statistic for 11- and 31-year moving means for rainfall indices for Grids-2, 4, 7 and 9. The year around which the highest $(\mathrm{H}) /$ lowest $(\mathrm{L})$ of 11-year moving mean has occurred are indicated by thin letters, while highest $\left(\mathrm{H}^{\prime}\right)$ / lowest $\left(\mathrm{L}^{\prime}\right)$ of 31 -year moving mean are indicated by bold letter. 
Hence, a consistent pattern was observed for these grids compared to Grid-7, which displayed erratic and fluctuating patterns. Further, in the past three decades (1983-2013), an increase in AMR has been observed over Grids- 8 and 9 . The trend analyses, as discussed above, revealed increasing trend in AAI for the Grids-2, 4, 6, 8 and 9, which are along/nearby the Tapi River. This would increase time of concentration of overland flow, thus, quicker concentration of peak discharges into the river.

\section{Conclusions}

The trend analyses of total annual rainfall, annual maximum rainfall and average annual rainfall intensity have been reported for Lower Tapi basin, India using the gridded rainfall data for the period 1901 - 2013. Following conclusions are derived from foregoing study:

i. From the historical records, it is observed that the southern part of the Lower Tapi basin experiences more rainfall compared to the rest of the basin. The Grids-2, 4 and 9 received average annual rainfall more than $1400 \mathrm{~mm}$ over the past century.

ii. The rainfall distribution across Lower Tapi basin shows that Grids-2, 4 and 9 experienced wet periods more than $29 \%$ of times, while Grid- 7 experienced dry periods almost $55 \%$ of times during the past century.

iii. The total annual rainfall has been found to increase across all the 9 grids in the basin. However, significant increasing trend is observed at Grids- 8 and 9, having trend slopes of 0.356 and 0.257 $\mathrm{mm} / \mathrm{year}$ respectively. It is seen that the said two grids encompass the urban area of Surat city, and increase in rainfall can be attributed to excessive urbanization also.

iv. The annual maximum rainfall has been found to increase at 7 out of 9 grids, while decreasing trends are observed at two remaining grids. The ITA plots reveals overall increasing trend in AMR, however, decreasing trend is observed in rainfall of higher magnitudes across most of the grids. Also, the rainfall intensity has been found to increase at 8 out of 9 grids in the basin, which could escalate the frequency of urban floods in near future.

v. The Cramer's test applied on 11- and 31-year moving average series revealed an increase in TAR, AMR and AAI across Grids-8 and 9 in the recent decades (1983-2013).

\section{Acknowledgements}

The first author gratefully acknowledges the financial support received from Department of Science and Technology (DST), Ministry of Science and Technology, Government of India vide their letter no. DST/INSPIRE Fellowship/2015/IF150634 dated January 11, 2016. The first author also acknowledges Science and Engineering Research Board (SERB), DST, Government of India for providing travel grant to attend HIC 2018 International Conference at Palermo, Italy. The authors appreciate the infrastructural and resourceful support provided by Centre of Excellence $(\mathrm{CoE})$ on "Water Resources and Flood Management", TEQIP-II, Ministry of Human Resources Development (MHRD), Government of India, for conducting the study reported in the paper. The authors are thankful to India Meteorological Department (IMD), Pune for providing data used in the present study. The first author also acknowledges the resourceful help received from Ms. Sahana V., Ms. Navya C. and Dr. V. D. Loliyana in data extraction. 
Rainfall Trends over the Past Century for Tropical Climatic Region in ...P. J. Sharma and P. L. Patel

\section{References}

Burn, D. H., and Elnur, M. A. H. (2002). Detection of hydrologic trends and variability. Journal of Hydrology, 255(1-4), 107-122.

Central Ground Water Board (2013). District ground water brochure - Surat district, Gujarat state, New Delhi.

Dash, S. K., Kulkarni, M. A., Mohanty, U. C., and Prasad, K. (2009). Changes in the characteristics of rain events in India. Journal of Geophysical Research: Atmospheres, 114(D10).

Dave, H. (2017). Characteristics of intense rainfall over Gujarat State (India) based on percentile criteria. Hydrological Sciences Journal, 62(12), 2035-2048.

Ghosh, S., Luniya, V., and Gupta, A. (2009). Trend analysis of Indian summer monsoon rainfall at different spatial scales. Atmospheric Science Letters, 10(4), 285-290.

Ghosh, S., Vittal, H., Sharma, T., Karmakar, S., Kasiviswanathan, K. S., Dhanesh, Y., Sudheer K.P. and Gunthe, S. S. (2016). Indian summer monsoon rainfall: Implications of contrasting trends in the spatial variability of means and extremes. PloS One, 11(7), e0158670.

Goswami, B. N., Venugopal, V., Sengupta, D., Madhusoodanan, M. S., and Xavier, P. K. (2006). Increasing trend of extreme rain events over India in a warming environment. Science, 314(5804), 14421445.

Guhathakurta, P., and Rajeevan, M. (2008). Trends in the rainfall pattern over India. International Journal of Climatology, 28(11), 1453-1469.

Hamed, K. H., and Rao, A. R. (1998). A modified Mann-Kendall trend test for autocorrelated data. Journal of Hydrology, 204(1-4), 182-196.

He, Y., Tian, P., Mu, X., Gao, P., Zhao, G., Wang, F., and Li, P. (2017). Changes in daily and monthly rainfall in the Middle Yellow River, China. Theoretical and Applied Climatology, 129(1-2), 139-148.

Hirsch, R. M., Slack, J. R., and Smith, R. A. (1982). Techniques of trend analysis for monthly water quality data. Water Resources Research, 18(1), 107-121.

Kale, V. S., and Hire, P. S. (2004). Effectiveness of monsoon floods on the Tapi River, India: role of channel geometry and hydrologic regime. Geomorphology, 57(3-4), 275-291.

Kale, V. S., Ely, L. L., Enzel, Y., and Baker, V. R. (1994). Geomorphic and hydrologic aspects of monsoon floods on the Narmada and Tapi Rivers in central India. In Geomorphology and Natural Hazards, pp. 157-168.

Kendall, M. G. (1975). Rank correlation methods, Charles Griffin, London.

Lehmann, E. L. (1975). Nonparametrics: Statistical Methods Basedon Ranks, Holden-Day, San Francisco.

Mann, H. B. (1975). Nonparametric tests against trend, Econometrica, 13, 245-259.

Martinez, C. J., Maleski, J. J., and Miller, M. F. (2012). Trends in precipitation and temperature in Florida, USA. Journal of Hydrology, 452, 259-281.

Pai, D. S., Sridhar, L., Rajeevan, M., Sreejith, O. P., Satbhai, N. S., and Mukhopadhyay, B. (2014). Development of a new high spatial resolution $(0.25 \times 0.25)$ long period $(1901-2010)$ daily gridded rainfall data set over India and its comparison with existing data sets over the region. Mausam, 65(1), $1-18$.

Peel, M. C., Finlayson, B. L., and McMahon, T. A. (2007). Updated world map of the KöppenGeiger climate classification. Hydrology and Earth System Sciences Discussions, 4(2), 439-473.

Prakash, S., Sathiyamoorthy, V., Mahesh, C., and Gairola, R. M. (2013). Is summer monsoon rainfall over the west coast of India decreasing?. Atmospheric Science Letters, 14(3), 160-163.

Roxy, M. K., Ghosh, S., Pathak, A., Athulya, R., Mujumdar, M., Murtugudde, R., Terray, P. and Rajeevan, M. (2017). A threefold rise in widespread extreme rain events over central India. Nature Communications, 8(1), 708. 
Rainfall Trends over the Past Century for Tropical Climatic Region in ...P. J. Sharma and P. L. Patel

Şen, Z. (2011). Innovative trend analysis methodology. Journal of Hydrologic Engineering, 17(9), 1042-1046.

Sharma, P. J., Loliyana, V. D., Nagpal, G., Resmi, S. R., Tripathi, A., Timbadiya, P. V., and Patel, P. L. (2015). Investigation of Long-Term Trends and Temporal Variability of Rainfall in Surat District, Gujarat, In Proceedings India Water Week 2015, New Delhi.

Sharma, P. J., Loliyana, V. D., Resmi, S. R., Timbadiya, P. V., and Patel, P. L. (2017). Spatiotemporal trends in extreme rainfall and temperature indices over Upper Tapi Basin, India. Theoretical and Applied Climatology, pp. 1-26. https://doi.org/10.1007/s00704-017-2343-y.

Sharma, P. J., Patel, P. L., and Jothiprakash, V. (2016). Efficient discretization of state variables in stochastic dynamic programming model of Ukai reservoir, India. ISH Journal of Hydraulic Engineering, 22(3), 293-304.

Soro, G. E., Noufé, D., Goula Bi, T. A., and Shorohou, B. (2016). Trend analysis for extreme rainfall at sub-daily and daily timescales in Côte d'Ivoire. Climate, 4(3), 37.

Timbadiya, P. V., Patel, P. L., and Porey, P. D. (2014). A 1D-2D coupled hydrodynamic model for river flood prediction in a coastal urban floodplain. Journal of Hydrologic Engineering, 20(2), 05014017 1-18.

W. M. O. (1966). Climatic Change, World Meteorological Organization Technical Note 79, WMO No. 195-TP-100, Geneva, p. 79.

www.censusindia.gov.in/2011 visited on 24/02/2018.

Yoo, C. (2006). Long term analysis of wet and dry years in Seoul, Korea. Journal of Hydrology, 318(1-4), 24-36.

Yue, S., and Hashino, M. (2003). Temperature trends in Japan: 1900-1996. Theoretical and Applied Climatology, 75(1-2), 15-27. 